\title{
Early Adopters of Electronic Prescribing Struggle to Make Meaningful Use of Formulary Checks and Medication History Documentation
}

\author{
Jesse C. Crosson, PhD, Anthony J. Schueth, MS, Nicole Isaacson, PhD, MSS, \\ and Douglas S. Bell, MD, PhD
}

Introduction: Use of electronic prescribing (e-prescribing) can improve safety and reduce costs of care by alerting prescribers to drug-drug interactions, patient nonadherence to therapies, and insurance coverage information. Deriving these benefits will require clinical decision support based on presentation of accurate and complete formulary and benefit (F\&B) and medication history (RxH) data to prescribers, but relatively little is known about how this information is used in primary care.

Methods: This is a multimethod comparative case study of 8 practices, which were selected to ensure practice size and physician specialty variation, implementing a stand-alone e-prescribing program. Field researchers observed prescription workflow and interviewed physicians and office staff.

Results: Before implementation, few prescribers reported using F\&B references when making medication choices; all used paper-based methods for tracking medication history. After implementation, some prescribers reported using F\&B data to inform medication choices but missing information reduced confidence in these resources. Low confidence in RxH data led to paper-based workarounds.

Conclusions: Challenges experienced with formulary checks and RxH documentation led to prescriber distrust and unwillingness to rely on e-prescribing-based information. Greater data accuracy and completeness must be assured if e-prescribing is to meet meaningful use objectives to improve the efficiency and safety of prescribing in primary care settings. (J Am Board Fam Med 2012;25:24-32.)

Keywords: Electronic Prescribing, Meaningful Use, Practice-based Research, Primary Health Care

This article was externally peer reviewed.

Submitted December 12, 2010. Revised version submitted September 21, 2011. Accepted for publication September 23, 2011.

From the Research Division, Department of Family Medicine and Community Health, UMDNJ-Robert Wood Johnson Medical School, Somerset, NJ (JCC, NI); Pointof-Care Partners, LLC, Coral Springs, FL (AJS); Counseling, ADAP and Psychiatric Services, Rutgers University, New Brunswick, NJ (NI); RAND Corporation, Santa Monica, CA (DSB); and the Division of General Internal Medicine and Health Services Research, Department of Medicine, David Geffen School of Medicine at UCLA, Los Angeles, CA (DSB).

Funding: This research was supported by the US Agency for Health Care Research and Quality and the Centers for Medicare and Medicaid Services, grant no. 1 U18 HS016391-01.

Prior presentation: Preliminary findings from this study were presented at the 35 th annual meeting of the North American Primary Care Research Group, October 20-23, 2007, Vancouver, British Columbia, Canada.

\section{See Related Article on Page 5.}

The use of electronic prescribing (e-prescribing) offers the potential to improve the quality, safety, and cost effectiveness of medical care by reducing the risk of adverse drug events and medication errors. ${ }^{1-7}$ However, use of this technology remains in the early adoption phase, ${ }^{8,9}$ recently representing approximately $20 \%$ of eligible US prescriptions and renewals. ${ }^{10,11}$ In recognition of the potential for this technology to improve care, the Medicare Prescription Drug Improvement and Modernization Act of 2003 included a mandate that health plans and pharmacies participating in providing the new Medicare prescription drug benefit support e-prescribing. ${ }^{12}$ More recently, the newly finalized core criteria for the "meaningful use" of health

Conflict of interest: none declared.

Corresponding author: Jesse C. Crosson, 1 World's Fair Drive, Room 1500, Somerset, NJ 08873 (E-mail: jesse.crosson@umdnj.edu). 
information technologies established under the Health Information Technology for Economic and Clinical Health provisions of the American Recovery and Reinvestment Act of 2009 include requirements for the electronic transmission of prescriptions and the maintenance of a medication history list. ${ }^{13-16}$ Along with these core criteria, the Office of the National Coordinator for Health Information Technology included in the "menu" set of criteria the implementation of drug formulary checks (see Table 1). Technical standards for eprescribing systems have been adopted to support these functions, but relatively little is known about how prescribers use the information communicated by these standards in prescribing practice. ${ }^{17}$

The formulary and benefit $(\mathrm{F} \& \mathrm{~B})$ standard is designed to provide prescribers with information at the point of care to make informed treatment decisions, taking into account the costs to the patient of various treatment options. Using the standard, payers can communicate information about what is approved for insurance coverage (ie, "on formulary"); which medication alternatives are preferred by a particular health plan; patient copayment amounts; benefit-related exclusions (eg, patient age or sex, quantity limitations, step therapies, medical necessity documentation requirements); and requirements for prior authorization before prescribing certain medications. Communication of this information could reduce medication-related health costs by helping prescribers choose the most cost-effective medications for their patients, ${ }^{18}$ thus potentially improving patient adherence. ${ }^{19}$ Accurate formulary information also could reduce work in ambulatory care practices by reducing or eliminating calls from pharmacies for responses to formulary-based rejections of insurance coverage, which currently are determined at the pharmacy and then communicated by telephone or fax communication to the prescriber for remedial action. ${ }^{19,20}$ Evidence does show that when doctors prescribe "on formulary" medications, patients are more likely to follow regimens, perhaps because of lower costs. $^{21,22}$ The medication history $(\mathrm{RxH})$ standard offers the option of alerting prescribers to potential drug-drug interactions or patient nonadherence to therapies through the inclusion of $\mathrm{RxH}$ information derived from prescription medication insurance claims data, thus including both electronic and paper prescriptions written by other prescribers. ${ }^{19,23}$

Despite the ongoing policy commitment to eprescribing, relatively little is known about how e-prescribing system-based $\mathrm{F} \& \mathrm{~B}$ and $\mathrm{RxH}$ information is used in ambulatory care settings, especially in smaller private practices, and how this differs from both planned usage and usage of paper-based resources. ${ }^{24}$ Previous studies have found that variation in the implementation of health information technologies, such as electronic medical

\section{Table 1. Meaningful Use Objectives Relating to Ambulatory Electronic Prescribing}

\begin{tabular}{lc}
\hline $\begin{array}{l}\text { Health Outcomes Policy } \\
\text { Priority }\end{array}$ & Stage 1 Objectives \\
\hline $\begin{array}{l}\text { Core set } \\
\text { Improving quality, safety, } \\
\text { efficiency, and reducing } \\
\text { health disparities }\end{array}$ & $\begin{array}{c}\text { Implement drug-drug and drug-allergy } \\
\text { interaction checks } \\
\text { Generate and transmit permissible } \\
\text { prescriptions electronically }\end{array}$
\end{tabular}

Maintain an active medication list

Maintain an active medication allergy list

Menu set

Improving quality, safety, efficiency, and reducing health disparities
Implement drug-formulary checks
Stage 1 Measures

The EP must attest that this function is enabled for the entire reporting period

More than $40 \%$ of all permissible prescriptions written by the EP are transmitted electronically using certified technology

More than $80 \%$ of all unique patients seen by the EP have at least one entry (or an indication that the patient is not currently taking any medication) recorded as structured data

More than $80 \%$ of all unique patients seen by the EP have at least one entry (or an indication that the patient has no known medication allergies) recorded as structured data

The EP must attest that this function is enabled and have access to at least one drug formulary for the entire reporting period

EP, eligible professional.

Adapted from Table 2 of Ref. 13. 
records and e-prescribing, and unrealistic expectations about the capabilities of these systems before implementation contributes to suboptimal usage, indicating that understanding actual rather than planned usage is necessary for accurately determining the effectiveness of health information technology for achieving expected gains. ${ }^{25,26}$ As part of the pilot testing of e-prescribing standards, we evaluated the use of $\mathrm{F} \& \mathrm{~B}$ and $\mathrm{RxH}$ information provided by 2 e-prescribing systems used in ambulatory care practices, and we report here the actual usage of these data by clinicians and the extent to which these early adopters were able to meet the objectives of the meaningful use criteria established for e-prescribing in new federal legislation. ${ }^{19,24,27,28}$

\section{Methods}

We conducted a comparative case study of ambulatory medical practices that had not adopted an electronic health record (EHR) to assess how $\mathrm{RxH}$ and $\mathrm{F} \& \mathrm{~B}$ information was handled before and after the scheduled installation of one of 2 stand-alone e-prescribing systems incorporating e-prescribing F\&B and RxH standards: Caremark's iScribe system (Scottsdale, AZ) and Allscripts' TouchScript system (Chicago, IL). (Because the study was not designed to evaluate specific program features, the programs are blinded as program A or B in Table 2). The data collection and analysis procedures used in this study previously have been described in detail. ${ }^{26}$ As a brief summary, we identified a sample of 12 ambulatory medical practices selected to ensure a mix of physician specialty and practice size from a list of those scheduled to implement either of two commercial e-prescribing programs: the Caremark iScribe or the Allscripts TouchScript systems. Ho- rizon Blue Cross and Blue Shield of New Jersey sponsored system implementation, covering the costs of hardware, software, installation, training, ongoing support, and prescriber honoraria to encourage e-prescribing use in practices that voluntarily signed up for the program. ${ }^{29}$ Before implementation and again approximately 3 months after scheduled implementation, field researchers visited each practice for 2 to 3 days and used observation and interview guides to observe prescription-related work and conduct key informant and in-depth interviews with practice members. ${ }^{30,31}$ At baseline and follow-up, physicians and practice staff (including medical assistants, nurses, receptionists, and office managers) were selected for in-depth interviews based on their leadership roles within the practice organization or their involvement in prescription workflow. Field researchers with backgrounds in medical anthropology and labor relations were trained by the lead author (JCC) to ensure standard data collection procedures at baseline and follow-up. These field researchers then conducted key informant interviews with other members of the practice to assess organizational preparation for and adaptation to e-prescribing use. After initial data collection, 10 practices successfully installed e-prescribing; 2 later discontinued use. ${ }^{26}$ Follow-up data collection for the results reported here focused on assessing practice adaptations to e-prescribing in the 8 practices that had sustained e-prescribing use. Prescribers and practice staff interviewed at baseline were re-interviewed at follow-up, except in a few instances where interviewees had left the practice.

Interview transcripts and field notes were entered into ATLAS.ti (Windows version 6.0.23, Sci-

Table 2. Participating Practices

\begin{tabular}{llll}
\hline Practice Specialty & Physicians (n) & Staffing & e-Rx Program \\
\hline Family medicine & 3 & 1 OM, 3 MAs, 4 S & B \\
& 4 & 1 OM, 1 LPN, 4 S & A \\
General internal medicine & 2 & 1 OM, 2 LPNs, 3 MAs, 3 S & B \\
& 2 & 1 OM, 1, LPN, 1 MA, 4 S & B \\
Obstetrics and gynecology & 1 & 1 OM & A \\
\hline
\end{tabular}

Caremark's iScribe system and Allscripts' TouchScript system were blinded in the study as either program A or B.

e-Rx, electronic prescribing; LPN, licensed practical nurse; MA, medical assistant; OM, office manager; RN, registered nurse; S = support staff including receptionists. 
entific Software Development, Berlin, Germany), and a diverse team of investigators including medical professionals, social scientists, and industry experts coded text data using a template organizing style based on observation and interview guides. ${ }^{32}$ A process of group and distributed coding of data resulted in substantial agreement $(K=0.72)$ on the meaning and application of codes before data analysis. $^{26,33}$ The lead author (JCC) then analyzed coding reports containing text segments relating to $\mathrm{RxH}$ and $\mathrm{F} \& \mathrm{~B}$ functions to determine common themes and identify representative text segments. The analyses and selection of these segments were then checked with the coauthors (AJS, NI, DSB) to ensure validity.

\section{Results}

Both of the e-prescribing programs used in the ambulatory care sites visited for the research reported here received formulary information and $\mathrm{RxH}$ data through the currently mandated standards. Practices ranged in size from 1 to 4 physicians and included general internal medicine, family medicine, and obstetrics and gynecology practices that had adopted either of the 2 standalone e-prescribing systems (see Table 2). Practices were all independent physician-owned, did not use EHRs, and were located in urban and suburban communities. All practices had indicated an interest in using a stand-alone e-prescribing program through their enrollment in the health plan-sponsored implementation support program and voluntarily enrolled in the program. Both e-prescribing programs were represented among the 8 practices successfully using an e-prescribing system practicewide at follow up. Use of $\mathrm{F} \& \mathrm{~B}$ and $\mathrm{RxH}$ resources varied across these sites at baseline. After implementation of the e-prescribing programs, we observed uneven use of electronic $\mathrm{F} \& \mathrm{~B}$ and $\mathrm{RxH}$ information across the practice sites. This uneven usage was common to both e-prescribing systems used in this study (see Table 3 for representative quotes).

\section{Formulary and Benefit}

At baseline, practices reported using a variety of paper and electronic resources to identify formulary status, drug coverage, copayment information, and preferred medication choices for patients with particular insurance plans. The use of these re- sources, including health plan mailings and electronic resources such as Epocrates (Epocrates, Inc., San Mateo, CA), was highly uneven. Many reported that the information is very complex and, because of constantly changing drug benefits, often unreliable. Faced with this complexity and unreliability, many reported ignoring $\mathrm{F} \& \mathrm{~B}$ information received from health plans or other sources and relying on patients or pharmacists to alert them to instances where medication costs or other health plan considerations made selection of an alternative medication preferable. Finally, there was tendency to rely on patients' communication of F\&B-related messages that the pharmacy receives from the payer and an expectation from some that e-prescribing, once implemented, would help them to better manage this information and use it to help reduce patient costs.

At follow-up, despite implementation of eprescribing with standard underlying $\mathrm{F} \& \mathrm{~B}$ information, variable use of $F \& B$ information remained; some prescribers reported that they relied on the new system whereas others continued to ignore formulary information regardless of the source. Some prescribers were convinced of the accuracy of the information and claimed to use it regularly. However, others reported getting misinformation from the program, which led to additional work in the practice; thus, they relied on pharmacists to determine what is covered for each patient.

\section{Medication History}

At baseline, all practices were using paper-based systems for tracking the medications that patients had taken or were currently taking. A commonly reported method for collecting this information was to ask patients to report their current medications at each office visit. Others relied on nursing or medical support staff to document current medications but thought that their lists were likely incomplete because of gaps in patients' knowledge about their own medications. Others thought that their medication lists were mostly complete and that prescribers or pharmacists consistently averted drug-drug and drug-allergy interactions. In both cases, the physicians did not seem to believe their current record-keeping systems were in need of improvement.

At follow-up, the e-prescribing systems for tracking $\mathrm{RxH}$ were widely reported to be unreli- 
Table 3. Perceptions of Prescription-Related Information Before And After Implementation Of Electronic Prescribing

\begin{tabular}{c} 
Before e-Rx \\
\hline Formulary and benefit $\quad$ "Periodically we get those [formulary lists], \\
but I ... throw them out because they \\
change so frequently, and we have so \\
many insurance plans... I glance through \\
them ... just to see what the flavor of the \\
month is, and then [it] goes in the \\
wastebasket." \\
"We do get formularies ... but ... the HMOs \\
have dozens or hundreds of plans each \\
and different formularies for each one and \\
by the time we get anything, it's obsolete \\
anyway."
\end{tabular}

"The drug reps ... come in and say, 'oh, we have this drug and it's covered on all the plans so remember our drug'... we don't have a book in the office that says 'this is covered by this.'"

“That part [of Epocrates] ... I don't use at all ... because I try not to let that cloud how I'm prescribing the medication. ... [But] I will change medications if, for financial reasons, the patient can't afford."

"[Currently] we just rely on the patient saying, 'Hey, it wasn't covered.' But, do we look at the lists ...? No ... But, I know, those computer things will help a lot if you try to write [a prescription] and it says, 'Hey, it's not allowed.'”

Medication history

"We don't have that in any organized way right now. So basically it's up to the doctor at each visit to review the meds and record them ... We're careful if we're going to prescribe something for someone ... but on the chart it's not real systematized."

"A lot of patients don't actually know what medicines they're taking."

“...very up-to-date ... very complete."

“...pretty much up-to date most of the time."
With e-Rx

"The computer will tell me ... which ones are preferred. ... If a patient is going to be paying 200 bucks for a prescription when I can give them something for 20 bucks, I'd rather do that if they are bio-equivalents."

"[The physicians] would pull it up on the [e-prescribing system] and it would say first tier, second tier, third tier covered ... and the pharmacy would call and say 'no, it's not'. And I don't know how many times I had doctors standing on one side of me, the pharmacist on the phone and the two of them bickering back and forth."

"They're not all in [the e-prescribing system] so I'm just letting it default to [one health plan] and once it gets to the pharmacy, the pharmacies will sort it out."

"It really hasn't changed my prescribing habits that much."
"A patient is on 10 drugs and I've given 3 drugs [with the e-prescribing system] ... then all I see is those 3."

"If a person's seeing a cardiologist [who is not using e-prescribing] ... is on heart medication, blood pressure medication, those medicines are not in the system."

"We still have to write [the medication] in the chart ... that is the real drawback."

e-Rx, electronic prescribing.

able, and most continued using paper record-keeping systems to track RxH. Part of the reason may have been the belief on the part of prescribers that there was incomplete capture of prescription information because of the use of both paper and electronic systems for prescribing. In addition, some physicians mistakenly thought that if their patients were seeing other physicians who do not use e-prescribing systems then their other prescriptions would not be in the system. Finally, the $\mathrm{RxH}$ provided by these systems is separate from medications that are entered into the medication list by the provider and typically are provided as a separate list. Because none of the practices used an electronic medical record system, dual record keeping was required. This dual record-keeping system, coupled with physicians' beliefs that the $\mathrm{RxH}$ information represented in the e-prescribing system was incomplete, limited the potential of the technology to provide infor- 
mation that could be used to inform physician/ patient discussions of the importance of medication adherence or the exploration of potential barriers to adherence.

\section{Discussion}

Among a group of voluntary early adopters of eprescribing technology, we found uneven use of both $\mathrm{F} \& \mathrm{~B}$ and $\mathrm{RxH}$ data by prescribers and support staff and widespread concerns about the accuracy, completeness, and usefulness of the data presented through these systems. Our findings indicate that many current e-prescribers likely will struggle to use these data to improve medication management in their practices even though they may manage to meet the stage 1 meaningful use criteria for $F \& B$ and $\mathrm{RxH} .{ }^{14}$ These findings add depth to those from several previous studies. Physician surveys and other recent studies have found relatively large numbers of e-prescribers who report being unable to identify prescriptions written by other prescribers in their system, despite the fact that such information is generated from prescription claims databases and thus should be available in any standards-based e-prescribing system. ${ }^{24,34-36}$ There are likely several underlying causes for the inadequacy of these data. $\mathrm{RxH}$ and $\mathrm{F} \& \mathrm{~B}$ information are often incomplete or erroneous because of challenges in correctly identifying patients using current technical standards for electronic determination of insurance eligibility, as well as the more than 40 million uninsured patients in the US who lack $\mathrm{RxH}$ data because it is based on insurance claims information. ${ }^{19}$ Our findings provide evidence that these coverage gaps have real effects on ambulatory care delivery, which limits both the potential quality and safety gains from e-prescribing in these settings and likely will limit the ability of current e-prescribers to improve care systematically while meeting meaningful use criteria relating to $\mathrm{F} \& \mathrm{~B}$ and $\mathrm{RxH}$ functions.

Currently, pharmacy benefit management companies have disparate ways of providing and managing $\mathrm{F} \& \mathrm{~B}$ information, and the technical standard must be designed to support all them. This complexity is multiplied by the use of National Drug Codes as drug identifiers in the $\mathrm{F} \& \mathrm{~B}$ files, creating the need for dozens of or even hundreds of entries to cover each drug that is on or off the formulary. These complexities make maintaining and ensuring the ac- curacy of $F \& B$ information challenging for the data aggregators. ${ }^{19}$ As a result, formulary files typically are rife with potential and actual mistakes. In addition, health plans have a great deal of latitude in how they use the standard and must pay to publish their $\mathrm{F} \& \mathrm{~B}$ information themselves. Unless health plans are required to provide a full set of formulary information, some will only use selected elements of the standard or opt out. This means that, for the foreseeable future, formulary data may be missing or incorrect for a substantial number of insured patients. Furthermore, in an effort to present $\mathrm{F} \& \mathrm{~B}$ information in a simplified, consistent manner, some clinical software systems "normalize" F\&B data, collapsing multiple coverage and copayment tiers into categories such as "preferred," "on formulary" and "off formulary," thus limiting the utility of this coverage information for informing cost-effective medication choices. Finally, even those systems that use the F\&B standard receive only group-level rather than plan-level formulary information, thus providing incorrect coverage information for those patients whose coverage plans differ from those in the overall coverage group to which they belong. Given all these potential sources of error and incomplete data, many prescribers are not likely to rely on e-prescribing F\&B data when making medication choices and may continue to rely on pharmacies to identify insurance coverage problems. (Pharmacies access true plan-level coverage when submitting a prescription through the insurance companies' claim adjudication systems.) These problems will be present in any system using current technical standards for e-prescribing, including those integrated into full-function EHR systems.

Physicians in this study also experienced $\mathrm{RxH}$ information as inaccurate or incomplete and, as has been found in other studies, continued to rely on patients to provide this information. ${ }^{24,34}$ Because $\mathrm{RxH}$ data are returned after a successful check for insurance eligibility, failures to match patients with their insurance benefit information accurately or gaps in prescription claims data could prevent retrieval of accurate $\mathrm{RxH}$ data. ${ }^{19,37}$ Unless prescribers can obtain $\mathrm{RxH}$-related data consistently and reliably, it is unlikely that this technology will be able to meet the objectives of the core criteria of electronically maintaining an active medication list as required. Though prescribers may meet standards of meaningful use by having at least $80 \%$ of their 
patients with at least one entry as structured data on an electronic medication list, more complete data will be required before prescribers will rely on these lists to assist in providing high-quality clinical care. $^{14}$

Because this is a qualitative study of e-prescribing use in ambulatory settings, our findings are not intended to represent the prevalence of issues related to the use of e-prescribing-based F\&B and $\mathrm{RxH}$ data. However, the systems that we studied are widely used and based on accepted technical standards that remain in use; thus other systems likely present the same problems identified here. Another limitation of the study is that the practices examined here did not include multispecialty group practices or other large ambulatory care settings. However, the smaller practices observed here are of a size similar to those in which the majority of ambulatory care is delivered in the US, and the technical issues underlying our findings are present regardless of the size or integrated nature of the ambulatory practice setting. In addition, we do not have detailed information about prior experiences with computerized systems among practice members, and longer-term follow-up would be required to determine if practices subsequently developed effective methods for using $\mathrm{F} \& \mathrm{~B}$ or $\mathrm{RxH}$ data. The e-prescribing industry is rapidly changing and we evaluated the use of only 2 widely used stand-alone e-prescribing systems. Some of the challenges we identified may have evolved since the time of our data collection. For example, the e-prescribing products evaluated here likely have improved their user interfaces and displays of data since this study, and we did not formally evaluate usability-related issues that may have presented additional barriers to accessing these data. Others have found that users of standalone systems are less likely to check formularies or $\mathrm{RxHs}$ than those with prescribing systems integrated into their medical record system. ${ }^{38}$ However, the root causes of the problems we identified lie in the e-prescribing standards and technical gaps that have not been addressed to date. Furthermore, relatively low use of the functions supported by the $\mathrm{F} \& \mathrm{~B}$ and $\mathrm{RxH}$ standards persists among users of both stand-alone and integrated systems. ${ }^{38}$ Thus, the deficiencies and problems that we observed here likely remain in currently available e-prescribing systems. Finally, we do not have specific information about the number of users represented by each of the systems used in this study. However, they are widely used programs produced by 2 leading companies in the e-prescribing field and, in any case, the technical standards underlying them are the same as for other e-prescribing products.

\section{Conclusion}

The findings reported here provide evidence that physicians using e-prescribing systems perceive substantial data quality problems in the $\mathrm{F} \& \mathrm{~B}$ and $\mathrm{RxH}$ information they receive through these systems and that these problems lead them to discount or ignore the information provided. These problems present challenges for primary care practices meeting the meaningful use criteria established by the Health Information Technology for Economic and Clinical Health Act. Several policy actions are needed to improve these data. Revision of the standards is needed to address data quality issues inherent in the nature of the standards themselves. The reliance by providers using e-prescribing technology on prescription claims data to generate $\mathrm{RxH}$ data for use at the point of care also should be revisited, and alternative approaches that have been pilot tested, such as using pharmacy sales data, ${ }^{39}$ should be expanded. The information communicated by e-prescribing standards should be evaluated regularly to ensure that the quality of information is sufficiently high to aid clinical decision making and to meet other federal standards. In addition, prescribers will need to be trained in how best to integrate this information into clinical encounters. Until the technical and data quality problems we have identified here are addressed, it is likely that health system-level quality gains and efficiencies expected from e-prescribing use will be realized unevenly as practices struggle to meet the meaningful use policy objectives relating to e-prescribing.

We acknowledge the participation of Horizon Blue Cross and Blue Shield of New Jersey, Caremark, and Allscripts in this research project.

\section{References}

1. Ammenwerth E, Schnell-Inderst P, Machan C, Siebert $\mathrm{U}$. The Effect of electronic prescribing on medication errors and adverse drug events: a systematic review. J Am Med Inform Assoc 2008;15(5):585-600.

2. Weingart SN, Simchowitz B, Padolsky H, et al. An empirical model to estimate the potential impact of medication safety alerts on patient safety, health care 
utilization, and cost in ambulatory care. Arch Intern Med 2009;169(16):1465-73.

3. van Doormaal JE, van den Bemt PMLA, Zaal RJ, et al. The influence that electronic prescribing has on medication errors and preventable adverse drug events: an interrupted time-series study. J Am Med Inform Assoc 2009;16(6):816-25.

4. Kuo G, Phillips R, Graham D, Hickner J. Medication errors reported by US family physicians and their office staff. Qual Saf Health Care 2008;17(4): 286-90.

5. Fischer MA, Stedman MR, Lii J, et al. Primary medication non-adherence: analysis of 195,930 electronic prescriptions. J Gen Intern Med 2010;25(4): 284-90.

6. Kaushal R, Kern LM, Barrón Y, Quaresimo J, Abramson EL. Electronic prescribing improves medication safety in community-based office practices. J Gen Intern Med 2010;25(6):530-6.

7. Jani YH, Barber N, Wong IC. Paediatric dosing errors before and after electronic prescribing. Qual Saf Health Care 2010;19(4):337-40.

8. Rogers EM. Diffusion of innovations. 5th ed. New York: Free Press; 2003.

9. Friedman MA, Schueth A, Bell D. Interoperable electronic prescribing in the United States: a progress report. Health Aff (Project Hope) 2009;28(2): 393-403.

10. Surescripts. National Progress Report on e-prescribing. 2010. Available at http://www.surescripts.com/ about-e-prescribing/progress-reports/nationalprogress-reports.aspx. Accessed September 15, 2011.

11. Pevnick JM, Asch SM, Adams JL, et al. Adoption and use of stand-alone electronic prescribing in a health plan-sponsored initiative. Am J Manag Care 2010; 16(3):182-9.

12. Bell D, Friedman MA. E-prescribing and the medicare modernization act of 2003. Health Aff (Project Hope) 2005;24(5):1159-69.

13. Centers for Medicare \& Medicaid Services, Health and Human Services. Medicare and Medicaid programs; electronic health record incentive program. Final rule. Fed Regist 2010;75(144):44313-588.

14. Office of the National Coordinator for Health Information Technology, Department of Health and Human Services. Health information technology: initial set of standards, implementation specifications, and certification criteria for electronic health record technology. Final rule. Fed Regist 2010; 75(144):44589-654.

15. Blumenthal D, Tavenner M. The "meaningful use" regulation for electronic health records. N Engl J Med 2010;363:501-4.

16. Blumenthal D. Launching HITECH. N Engl J Med 2010;362(5):382-5.

17. Centers for Medicare and Medicaid Services, Human Services. Medicare program; standards for eprescribing under Medicare Part D and identifica- tion of backward compatible version of adopted standard for e- prescribing and the Medicare prescriptions drug program (version 8.1). Final rule. Fed Regist 2008;73(67):18917-42.

18. Fischer M, Vogeli C, Stedman M, Ferris T, Brookhart MA, Weissman J. Effect of electronic prescribing with formulary decision support on medication use and cost. Arch Intern Med 2008;168(22): 2433-9.

19. Bell DS, Schueth AJ, Guinan JP, Wu S, Crosson JC. Evaluating the technical adequacy of electronic prescribing standards: results of an expert panel process. AMIA Ann Symp Proc 2008:46-50.

20. Bell D, Cretin S, Marken RS, Landman AB. A conceptual framework for evaluating outpatient electronic prescribing systems based on their functional capabilities. J Am Med Inform Assoc 2004;11(1): $60-70$.

21. Shrank WH, Fox SA, Kirk A, et al. The effect of pharmacy benefit design on patient-physician communication about costs. J Gen Intern Med 2006; 21(4):334-9.

22. Shrank WH, Hoang T, Ettner SL, et al. The implications of choice: prescribing generic or preferred pharmaceuticals improves medication adherence for chronic conditions. Arch Intern Med 2006;166(3):332-7.

23. Tarn DM, Paterniti DA, Heritage J, Hays RD, Kravitz RL, Wenger NS. Physician communication about the cost and acquisition of newly prescribed medications. Am J Manag Care 2006;12(11):657-64.

24. Grossman JM, Gerland A, Reed MC, Fahlman C. Physicians' experiences using commercial e-prescribing systems. Health Aff (Project Hope) 2007; 26(3):w393-404.

25. Crosson JC, Stroebel C, Scott JG, Stello B, Crabtree BF. Implementing an electronic medical record in a family medicine practice: communication, decisionmaking, and conflict. Ann Fam Med 2005;3(4):307-11.

26. Crosson J, Isaacson N, Lancaster D, et al. Variation in electronic prescribing implementation among twelve ambulatory practices. J Gen Intern Med 2008; 23(4):364-71.

27. Centers for Medicare and Medicaid Services, Health and Human Services. Medicare program; e-prescribing and the prescription drug program. Final rule. Fed Regist 2005;70(214):67568-95.

28. Bell DS, Schueth AJ, Crosson JC, et al. Pilot testing of electronic prescribing standards. 2007. Available at http://healthit.ahrq.gov/portal/server.pt?Community $\mathrm{ID}=666 \&$ spaceID $=399 \&$ parentname $=\&$ control $=$ SetCommunity \& parentid $=\&$ PageID $=0 \&$ space $=$ CommunityPage\&in_tx_query $=$ Pilot + testing + of + electronic + prescribing + standards. Accessed August 21, 2009.

29. Crabtree BF, Miller WL, Stange KC. Understanding practice from the ground up. J Fam Pract 2001; 50(10):881-7. 
30. Dicicco-Bloom B, Crabtree BF. The qualitative research interview. Med Educ 2006;40(4):314-21.

31. Crabtree BF, Miller WL. Using codes and code manuals: a template organizing style of interpretation. In: Crabtree BF, Miller WL, eds. Doing qualitative research. 2nd ed. Thousand Oaks, CA: Sage Publications; 1999:163-77.

32. Landis JR, Koch GG. The measurement of observer agreement for categorical data. Biometrics 1977; 33(1):159-74.

33. Wang CJ, Patel MH, Schueth AJ, et al. Perceptions of standards-based electronic prescribing systems as implemented in outpatient primary care: a physician survey. J Am Med Inform Assoc 2009;16(4):493-502.

34. Lapane. e-Prescribing and Patient Safety. Am J Pharm Benefits 2011;1-11.

35. Grossman JM, Boukus ER, Cross DA, Cohen GR. Physician practices, e-prescribing and accessing information to improve prescribing decisions. Res Briefs 2011;(20):1-10.
36. Lapane K, Waring M, Schneider K, Dubé C, Quilliam B. A mixed method study of the merits of e-prescribing drug alerts in primary care. J Gen Intern Med 2008;23(4):442-6.

37. DesRoches CM, Agarwal R, Angst CM, Fischer MA. Differences between integrated and stand-alone eprescribing systems have implications for future use. Health Aff (Project Hope) 2010;29(12):2268-77.

38. Lapane K, Whittemore K, Rupp M, Dubé C, Jackson T, Dhavle A. Maximizing the effectiveness of e-prescribing between physicians and community pharmacies: Surescripts; 2006. Available at http:// www.google.com/url? sa $=$ t\& $r c t=j \& q=\& \operatorname{esrc}=$ $\mathrm{s} \& \mathrm{frm}=1 \&$ source $=$ web\& $\mathrm{cd}=1 \&$ ved $=0 \mathrm{CCsQFjAA} \&$ url $=$ http $\% 3 \mathrm{~A} \% 2 \mathrm{~F} \% 2$ Fhealthit.ahrq.gov $\% 2 \mathrm{Fportal} \%$ 2Fserver.pt\%2Fgateway\%2FPTARGS_0_227310_0_ 0_18\%2FSureScripts \% 2520-\% 2520Final\% 2520 Report.pdf\&ei=SwvATsiCA4jk0QHbxcjLBA\&usg= AFQjCNF14gIMzBKC8LfNCcMIvyN6eGG3GA\& sig2=i4F8FBSXP_IOlbF3QJf-ZQ. Accessed November 13, 2011. 